\title{
Proteomics of Bulked Rachides Combined with Documented QTL Uncovers Genotype Nonspecific Players of the Fusarium Head Blight Responses in Wheat
}

\author{
Jiajun Liu, Lei Li, Nora A. Foroud, Xuan Gong, Changcheng Li, and $\mathrm{Tao} \mathrm{Li}^{\dagger}$
}

First, second, fourth, fifth, and sixth authors: Jiangsu Provincial Key Laboratory of Crop Genetics and Physiology/Co-Innovation Center for Modern Production Technology of Grain Crops/Key Laboratory of Plant Functional Genomics of Ministry of Education, Yangzhou University, Yangzhou, Jiangsu 225009, China; and third author: Lethbridge Research and Development Centre, Agriculture and Agri-Food Canada, Lethbridge, AB T1J 4B1, Canada.

Accepted for publication 20 July 2018.

\begin{abstract}
Fusarium head blight (FHB) is a destructive disease of wheat that reduces yield and grain quality. High-throughput proteomic techniques have been used to identify a wide range of candidate proteins involved in host resistance. The majority of the published works on the proteomics of the wheat response to Fusarium graminearum infection are case specific. In the current study, a high-throughput quantitative label-free strategy was employed on bulked rachides of $F$. graminearum-infected wheat collected from multiple genotypes. Differentially accumulated proteins among the following four pools were identified: mock-inoculated FHBresistant accessions (RM), mock-inoculated FHB-susceptible accessions (SM), F. graminearum-inoculated FHB-resistant accessions (RFg), and

F. graminearum-inoculated FHB-susceptible accessions (SFg). Four pairs of comparisons were made: RFg versus RM, SFg versus $\mathrm{SM}$, RM versus $\mathrm{SM}$, and RFg versus SFg. Proteins were projected onto the consensus intervals of previously reported quantitative trait loci in the FHB-resistant pool by blasting against the Chinese Spring reference sequences. In addition to proteins previously reported in the host response to Fusarium spp., new candidates have emerged in association with resistance or susceptibility, including a group 3 late embryogenesis abundant as a resistancerelated protein and a purple acid phosphatase as a susceptibility protein. The protein atlas presented here provides new perspectives on the interaction between $F$. graminearum and wheat.
\end{abstract}

Fusarium head blight (FHB), mainly caused by Fusarium graminearum and related species, is a devastating disease of wheat worldwide. The fungus produces trichothecene mycotoxins such as deoxynivalenol (DON), which are harmful to humans and animals (Pestka 2010). Resistance to FHB is quantitative (Buerstmayr et al. 2009); as such, no wheat germplasm with immunity to this disease has been identified. The two best-described mechanisms of resistance are resistance to initial infection of the spike (type 1) and resistance to disease spread from spikelet to spikelet (type 2) (Schroeder and Christensen 1963). More than 100 quantitative trait loci (QTL) have been reported for FHB resistance (Buerstmayr et al. 2009; Liu et al. 2009). Perhaps the best-described source of resistance is the Sumai 3 Fhbl locus, recently described as a chimeric lectin (Rawat et al. 2016), which has been widely used in breeding programs around the world due to the strong contributions of this QTL, especially in type 2 resistance (Anderson et al. 2001; Cuthbert et al. 2006).

Proteomics strategies have led to the identification of various defense-related gene products involved in the host response. A reduction in carbon metabolism and photosynthesis gene products occurs prior to the upregulation of stress-related proteins (Wang

†Corresponding author: Tao Li; E-mail: taoli@yzu.edu.cn

Funding: This work was supported by the National Natural Science Foundation of China (31771772), State's Key Project of Research \& Development Plan for Breeding of Top-Seven Crops (2017YFD0100801); the Yangzhou Key Research and Development Program (YZ2016035), and the Priority Academic Program Development of Jiangsu Higher Education Institutions.

*The $\boldsymbol{e}$-Xtra logo stands for "electronic extra" and indicates that one supplementary figure and five supplementary tables are published online.

(c) 2019 The American Phytopathological Society et al. 2005). Oxidative burst and pathogenesis-related (PR) proteins have been linked both with susceptible and resistant responses of wheat and barley (Geddes et al. 2008; Zhou et al. 2005, 2006). Previous studies have all employed a two-dimensional polyacrylamide gel electrophoresis (2DE) approach and, although 2DE still offers some advantages over the gel-free methods (Rogowska-Wrzesinska et al. 2013), the throughput of 2DE does not match that of the latter.

Many of the "omics" studies in the FHB-host interaction are carried out in spikelets, which may limit the information provided on type 2 resistance. Type 2 resistance is important for delaying pathogen progression in the rachis; therefore, the rachis architecture likely plays a crucial role in shaping this form of resistance (Jansen et al. 2005; Kang and Buchenauer 2000). A bulked-sample analysis for omics studies can remove genotype-dependent variability from the data set (Zou et al. 2016). This work was carried out on bulked rachides from a panel of well-documented FHB-resistant (carrying type 2 resistance QTL) and FHB-susceptible wheat genotypes, in order to focus on the responses at the rachis node. Additionally, proteins were mapped to the genome-wide QTL, providing a panel of candidate genes for further investigations. Taking advantage of high-throughput proteomics techniques, this is the first study addressing the host response to $F$. graminearum at the rachis node by employing a bulked-sample analysis approach toward identification of candidate proteins involved in type 2 resistance in wheat.

\section{MATERIALS AND METHODS}

Plant material, inoculations, and sampling. Ten FHBresistant accessions with known resistance QTL were used, including Fhb1-NIL-R (Bernardo et al. 2012), Sumai 3 (Anderson et al. 2001), Wangshuibai (Lin et al. 2004; Yu et al. 2008b; Zhou et al. 
2004), Nyubai (Ban et al. 2008; Cuthbert et al. 2006), Ning7840 (Bai et al. 1999), Huangfangzhu (Li et al. 2012), Baishanyuehuang (Zhang et al. 2012), Huangcandou (Cai and Bai 2014), Taiwan wheat (Li et al. 2016a), and Tokai-66 (Yen et al. 2010). Each of these lines has consistently shown a high level of FHB resistance, with reported disease severities of less than $20 \%$. All of the resistant lines carry $F h b 1$ in addition to other resistance QTL. Six FHBsusceptible accessions, including Fhbl-NIL-S (Bernardo et al. 2012), Wheaton, Bobwhite, Jagger, Chinese Spring, and Clark, were previously shown to be highly susceptible to FHB, with disease severities greater than 60\% (Li et al. 2016a,b; Yu et al. 2006, 2008a). Wheat plants were grown in a greenhouse in Yangzhou, China, maintained at $22 \pm 5^{\circ} \mathrm{C}$ (day) and $17 \pm 2^{\circ} \mathrm{C}$ (night) with a $12-$ $\mathrm{h}$ photoperiod.

Plants were inoculated with macroconidial spores of an $F$. graminearum strain, isolate $\mathrm{Fg} 65$, collected in the province of Jiangsu. Macroconidia were produced in mung bean broth according to the protocol described by Bai et al. (1999). For each of the 16 accessions, 10 spikes were inoculated at early anthesis by injecting $10 \mu \mathrm{l}$ of the spore suspension (100 conidia $\left.\mu \mathrm{l}^{-1}\right)$ into a floret of the central spikelet in a spike. Mock-inoculated control plants were treated the same way, where $10 \mu \mathrm{l}$ of mung bean broth was used instead of spores. Inoculated spikes were individually covered with a thin plastic sandwich bag to provide the humidity required to initiate fungal infection. The rachides below the pathogen- and mock-inoculated spikelets were harvested 3 days postinoculation (dpi) and stored at $-80^{\circ} \mathrm{C}$ prior to protein and RNA extraction. Three independent biological replicates were prepared for each extraction.

Protein extractions. The rachides collected from each accession and treatment were ground to a powder in liquid nitrogen with a mortar and pestle. For each treatment, equal amounts of ground rachides from the 10 resistant accessions or the 6 susceptible accessions were combined for the extraction. Thus, for each of three replicates, four pools of ground tissue were generated: an FHBresistant pool (consisting of 10 resistant genotypes) following mock inoculation (RM) or inoculation with $F$. graminearum $(\mathrm{RFg})$, and an FHB-susceptible pool (consisting of 6 susceptible genotypes) following mock inoculation (SM) or inoculation with $F$. graminearum (SFg). Protein extraction was carried out by Shanghai Applied Protein Technology Co., Ltd., where a trichloroacetic acid (TCA)acetone precipitation method was employed. The ground rachis tissues were mixed with $5 \times$ volume of TCA-acetone (1:9) and proteins were precipitated at $-20^{\circ} \mathrm{C}$ for $4 \mathrm{~h}$. The precipitate was pelleted by centrifugation $\left(6,000 \times g, 40 \mathrm{~min}, 4^{\circ} \mathrm{C}\right)$ and the pellets were washed three times in cold acetone, air dried, and, finally, resuspended in $30 \times$ volume of STD buffer (4\% sodium dodecyl sulfate, $100 \mathrm{mM}$ Tris- $\mathrm{HCl}$, and $1 \mathrm{mM}$ dithiothreitol, pH7.6). Samples in STD buffer were boiled for $5 \mathrm{~min}$, sonicated, and then boiled again for $15 \mathrm{~min}$. In order to remove debris, samples were then spun at $14,000 \times g$ for $40 \mathrm{~min}$ and the supernatant passed through $0.22-\mu \mathrm{m}$ filters. Protein concentration was determined using a BCA Protein Assay Kit (Bio-Rad) and samples were stored at $-80^{\circ} \mathrm{C}$ prior to protein digestion and mass spectrometry (MS).

Sample preparation and MS. Protein digestion and MS were carried out at Shanghai Applied Protein Technology Co., Ltd. Filter-aided sample preparation digestion was performed according to Wiśniewski et al. (2009). Briefly, for each protein extraction, $200 \mu \mathrm{g}$ of protein in $30 \mu \mathrm{l}$ of STD buffer was transferred to an ultrafiltration unit with a 10-kDa molecular mass cutoff. STD buffer was removed by centrifugation-assisted washes carried out in UA buffer (8 M urea and $150 \mathrm{mM}$ Tris- $\mathrm{HCl}, \mathrm{pH} 8.0$ ). Reduced cysteine residues were then alkylated using $100 \mathrm{mM}$ iodoacetamide in $100 \mu \mathrm{l}$ of UA buffer. Following a 20 -min incubation, the filter was washed with UA buffer, then with $25 \mathrm{mM} \mathrm{NH}_{4} \mathrm{HCO}_{3}$. Finally, the protein was suspended in $40 \mu \mathrm{l}$ of $25 \mathrm{mM} \mathrm{NH}_{4} \mathrm{HCO}_{3}$ buffer and an on-filter digestion was carried out with $4 \mu \mathrm{g}$ of trypsin (Promega Corp.). Following an overnight incubation at $37^{\circ} \mathrm{C}$, peptides were eluted from the column and the filtrate was desalted on a $\mathrm{C} 18$ Cartridge (Empore SPE Cartridges C18 [standard density]), bed inner diameter $=7 \mathrm{~mm}$, and volume $=3 \mathrm{ml}$; Sigma). Desalted samples were concentrated by vacuum centrifugation and reconstituted in $40 \mu \mathrm{l}$ of $0.1 \%$ formic acid. The peptide concentration was estimated by near-UV absorption at $280 \mathrm{~nm}$, using an extinction coefficient of 1.1 of $0.1 \%$ (gram per liter) solution.

The MS experiment was carried out with an EASY-nLC (Proxeon Biosystems) instrument, equipped with a C18-reversed phase column (Thermo Scientific Easy Column, $10 \mathrm{~cm}$ long, $75 \mu \mathrm{m}$ inner diameter, and $3 \mu \mathrm{m}$ resin), and coupled to a $\mathrm{Q}$ Exactive Mass Spectrometer (Thermo Fisher Scientific). Samples $(5 \mu \mathrm{g})$ were loaded onto the column in solvent $\mathrm{A}(0.1 \%$ formic acid $)$ and eluted with an increasing concentration of solvent $\mathrm{B}(0.1 \%$ formic acid and $46.5 \%$ acetonitrile) as follows: linear gradient of 0 to $55 \%$ solvent B over $110 \mathrm{~min}$ and then 55 to $100 \%$ solvent B over $5 \mathrm{~min}$, followed by a washout at $100 \%$ solvent B for $5 \mathrm{~min}$ (flow rate of 250

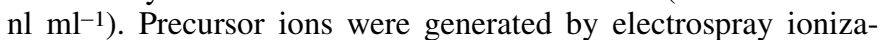
tion in positive ion mode. A data-dependent top-10 method was employed during the survey scans (300 to $1,800 \mathrm{~m} / \mathrm{z}$, with a resolution of 70,000 at $\mathrm{m} / \mathrm{z} 200$ ) to select for the most abundant precursor ions for high-energy collision-induced dissociation (HCD). The dynamic exclusion duration was set at $40 \mathrm{~s}$. A collision energy of $30 \mathrm{eV}$ was employed, and automatic gain control was set at $3 \times 10^{6}$ with a maximum injection time of $10 \mathrm{~s}$. The HCD resolution was 17,500 at $\mathrm{m} / \mathrm{z} 200$. The underfill ratio was set at $0.1 \%$.

Sequence database searching and data analysis. The MS data were analyzed by Shanghai Applied Protein Technology Co., Ltd. with MaxQuant software (version 1.3.0.5; Max Plank Institute of Biochemistry) (Cox and Mann 2008) and searched against Uniprot (137,970 total entries) (https://www.uniprot.org/). The following search parameters were employed: Main search parts per million $=6$; missed cleavage $=2 ; \mathrm{MS} / \mathrm{MS}$ tolerance $\mathrm{ppm}=20$; deisotopic $=$ TRUE; enzyme $=$ trypsin; database $=$ uniprot_Triticum 137970_20150724.fasta; fixed modification = carbamidomethyl $(C)$; variable modification $=$ oxidation $(\mathrm{M})$, acetyl $($ protein $\mathrm{N}$-term); decoy database pattern = reverse; $\mathrm{iBAQ}=\mathrm{TRUE}$; iBAQ min. ratio count $=1$; match between runs $=2$ min; peptide false discovery rate $(\mathrm{FDR})=0.01 ;$ and protein $\mathrm{FDR}=0.01$.

Label-free quantification was carried out using the MaxQuant software as previously described (Luber et al. 2010). Protein abundance was calculated based on the normalized label-free quantitation spectral intensity. Missing values were assigned in Perseus (Tyanova et al. 2016) (software version 1.3.0.4) by replacing missing values from a normal distribution to simulate low-abundance values in a typical MS performance. Differentially accumulated proteins were defined as those with at least a twofold difference for the mean ratio $(P<0.05)$. The sequences of the detected differentially accumulated proteins were searched locally against the SwissProt database using the National Center for Biotechnology Information BLAST+ client software (ncbi-blast-2.2.28+-win32. exe) to find homologous sequences for functional annotation. The top 10 blast hits $(\mathrm{E}$ values $<1 \mathrm{e}-3)$ for each query sequence were selected for Blast2GO2 (version 2.7.2) analysis and subsequent GO3 mapping and annotation.

Consensus QTL intervals and database construction. The intervals of previously reported QTL from each resistant wheat accession in the panel were compared and consensus QTL intervals were established (Buerstmayr et al. 2009; Liu et al. 2009). Peptides were first projected to the cDNA library of Chinese Spring (International Wheat Genome Sequencing Consortium 2014); then, the cDNA were blasted to the Chinese Spring reference sequences (https://wheat-urgi.versailles.inra.fr).

Primers from GrainGenes (https://wheat.pw.usda.gov) were selected for electronic polymerase chain reaction (e-PCR). The e-PCR program was used to provide a reliable graphical view of the primer positions, and parameters were set as follows, $-\mathrm{w} 9,-\mathrm{f} 1,-\mathrm{m}$ 100 , $-\mathrm{t} 3, \mathrm{D}=80$ to $500, n=2, \mathrm{G}=2, \mathrm{~T}=3$, and others were set 
as default. The source code for the e-PCR package is freely available (ftp://ncbi.nlm.nih.gov/pub/schuler/e-PCR/). The proteins that fell into the target QTL intervals are listed in Supplementary Table $\mathrm{S} 1$.

Quantitative PCR. Reverse-transcription quantitative PCR (RT-qPCR) was carried out for five genes of interest to investigate the consistency between transcript levels and corresponding protein accumulation of predicted gene products. RT-qPCR was performed using bulked RNA from exactly the same bulked samples used for proteomics to keep consistency. Total RNA was isolated and purified from each pool using TRIzol reagent (Invitrogen). cDNA synthesis was carried out with PrimeScript RT Reagent Kit with gDNA Eraser (Takara) according to the manufacturer's instructions. Primers were designed in Primer-BLAST (https://www.ncbi. nlm.nih.gov/tools/primer-blast) to amplify genes of interest (Supplementary Table S2), and actin (5'-GACAATGGAACCGGAAT GGTC-3' and 5'-GTGTGATGCCAGATTTTCTCCAT-3') was used as a housekeeping gene. RT-qPCR was carried out using SYBR premix Ex Taq (Takara) on an Applied Biosystems ViiA 7 Real-Time PCR system. The samples were incubated at $50^{\circ} \mathrm{C}$ for $2 \mathrm{~min}$, then $95^{\circ} \mathrm{C}$ for $5 \mathrm{~min}$, followed by 40 cycles of $95^{\circ} \mathrm{C}$ for $15 \mathrm{~s}$, $55^{\circ} \mathrm{C}$ for $30 \mathrm{~s}$, and $72^{\circ} \mathrm{C}$ for $45 \mathrm{~s}$. A melt curve was employed at $95^{\circ} \mathrm{C}$ for $15 \mathrm{~s}, 60^{\circ} \mathrm{C}$ for $1 \mathrm{~min}$, and $95^{\circ} \mathrm{C}$ for $15 \mathrm{~s}$. The experiment was carried out on three biological replicates for each pool, and the three technical replicates were included in the RT-qPCR. Relative expression of each gene was calculated using the $2^{-\Delta \Delta C T}$ formula (Livak and Schmittgen 2001). A multiple comparison analysis of relative expression data was performed with the Matlab software (R2014b) to determine significant differences, and a $P$-value cutoff of 0.05 was employed.

\section{RESULTS}

Protein identification. Label-free quantification resulted in the identification of 19,706 unique peptides and 4,627 proteins. Among the 4,627 proteins, the majority of the peptide sequence

coverage was less than $30 \%$ (Fig. 1A). Putative protein identifications were assigned based on at least one peptide match, where $20 \%$ of the proteins had five or more peptide hits, 1,825 proteins had two to four hits, and 1,865 proteins had only one peptide match (Fig. 1B). Putative protein names or functional categories were only assigned to those with multiple (two or more) peptide hits. Among all of the detected proteins, 2,766 proteins have predicted molecular mass of 20 to $60 \mathrm{kDa}, 774$ of 60 to $100 \mathrm{kDa}, 760$ of 1 to $20 \mathrm{kDa}$, and 327 of $>100 \mathrm{kDa}$ (Fig. 1C). Detected peptides were distributed across the wheat genome (Fig. 2): 6,488 peptides were mapped on the A genome, 5,943 peptides on the B genome, 4,468 peptides on the $\mathrm{D}$ genome, and the location of 2,807 were undetermined. In the seven homologous groups, group 2 had the largest number of peptides and group 7 had the lowest. In total, 1,508 peptides were mapped on chromosome $3 \mathrm{~B}$, which made up the largest proportion of peptides on the $\mathrm{B}$ genome.

Comparative analysis of wheat proteome. Differences in the abundance of proteins represented among the four pairs of the pools (RFg versus RM, SFg versus SM, RM versus $S M$, and RFg versus SFg) were analyzed (Fig. 3; Supplementary Fig. S1; Supplementary Table S3). In total, 237 proteins were differentially accumulated between the RFg and the RM pools, 238 between the SFg and the SM pools, 234 between the RM and the SM pools, and 206 between the RFg and the SFg pools. Thirty-eight common proteins were identified between the two pairs of the pools RFg versus RM and SFg versus SM. Thirty-nine proteins were in common between RM versus SM and RFg versus SFg. Gene ontology (GO) for differentially expressed proteins is presented in Figure 4 and Supplementary Table S4.

Fusarium-induced changes in protein accumulation in resistant or susceptible wheat. In total, 237 proteins differed significantly in abundance between the RFg and RM pools, among which 165 proteins were upregulated in the RFg pool. Among the proteins with two or more peptide hits, 126 were annotated based on GO terms, revealing that 36 differentially regulated proteins are involved in catalytic activity, 25 proteins are plastid components,

B
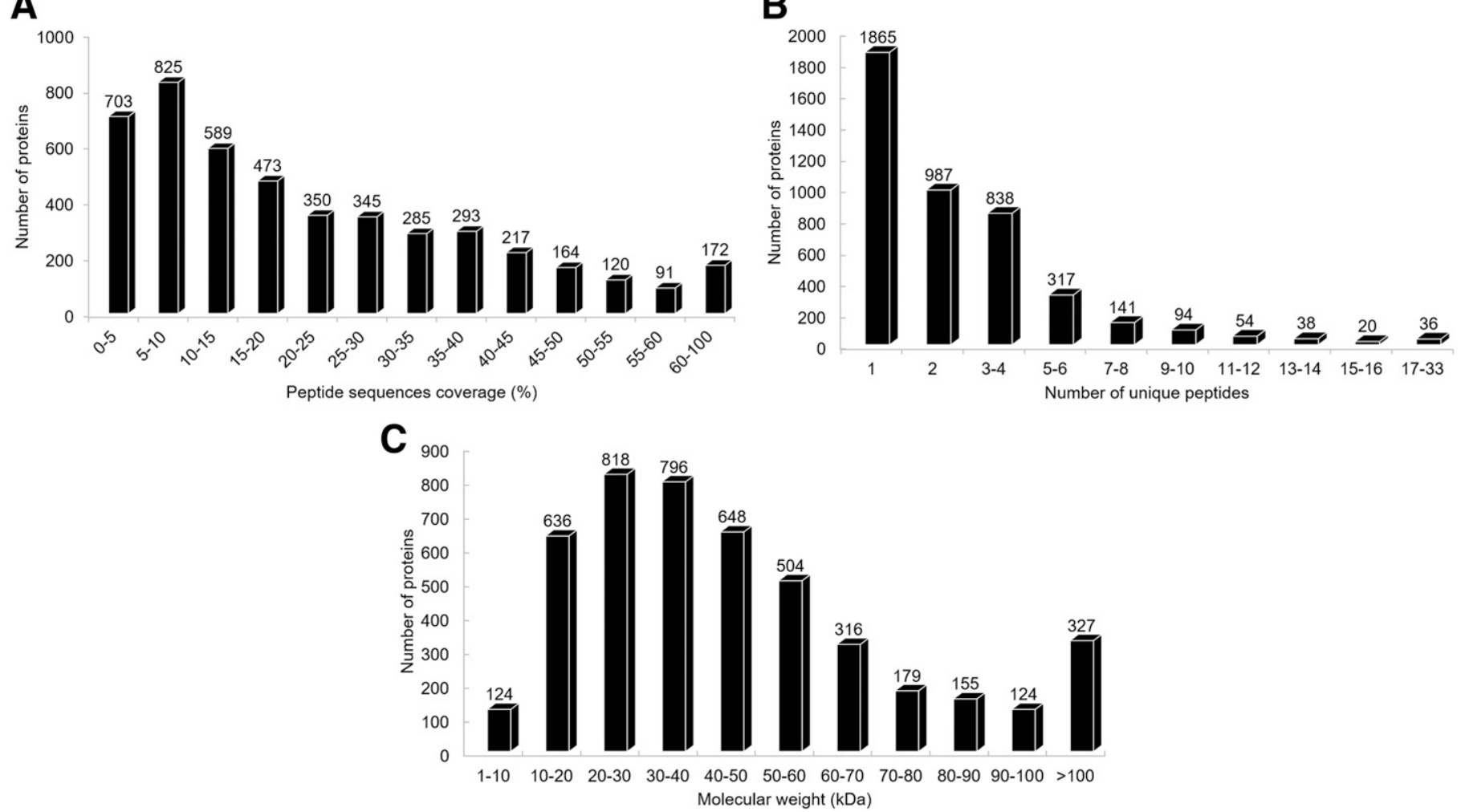

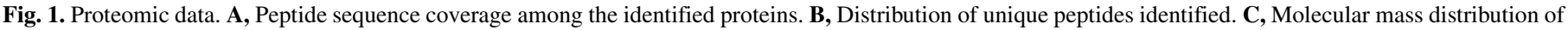
the identified proteins.

Vol. 109, No. 1, 2019 
and another 25 proteins are predicted to take part in cellular processes.

In the susceptible genotypes, 238 proteins were differentially accumulated between the SFg and SM pools. Among these, 150 putative proteins significantly increased in abundance in the $\mathrm{SFg}$ pool. $\beta$-1,3-Glucanase (PR-2) showed seven times higher accumulation in the SFg pool. Analysis of GO terms suggests that differentially accumulated proteins in the SFg versus SM pool are mainly involved in hydrolase activity and biosynthetic process.

Fusarium-induced changes in protein accumulation in common among resistant and susceptible wheat. Some commonalities were observed in the resistant versus susceptible response to Fusarium challenge. Peptides from 27 proteins were upregulated in both the RFg and SFg pools when compared with their respective mock-inoculated pools, and 6 proteins in common were downregulated in both RFg and SFg. PR-1, PR-2, peroxidase (POD) 12, and peptidyl-prolyl cis-trans isomerase (PPIase) were upregulated in both the RFg pool and SFg pool. A nonspecific lipidtransfer protein (nsLTP) was downregulated in RFg and SFg.

Fusarium-induced changes in protein accumulationComparison of resistant and susceptible wheat. In total, 206 protein profiles differed between the RFg and the SFg pools, where 75 proteins were higher in the RFg pool. Of the 206 proteins, 26 are predicted to partake in biosynthetic processes and 11 are involved in the stress response. Two proteins accumulated in RFg at three times the abundance of SFg: a photosystem II reaction center protein and a PR protein.

Comparison of Fusarium-induced host response proteins reported in the literature. To analyze agreements and differences with previously published studies, our results were compared with the proteins differentially enriched in response to Fusarium
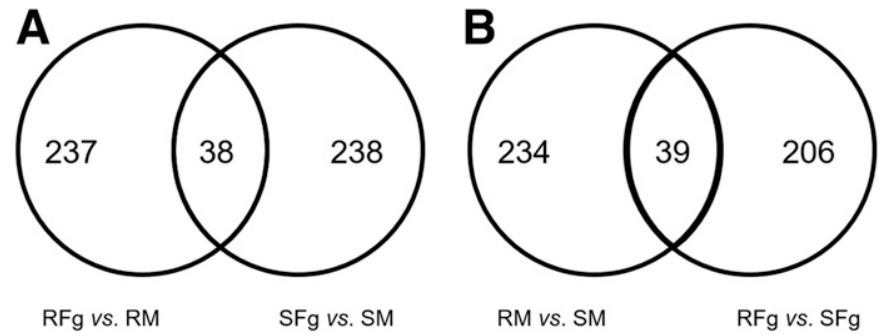

Fig. 3. Venn diagram depicting the number of differentially accumulated proteins. A, Effect of Fusarium spp. in resistant or susceptible accessions. B, Effect of inoculation with and without Fusarium spp. Pools: mock-inoculated Fusarium head blight (FHB)-resistant accessions (RM), mock-inoculated FHBsusceptible accessions (SM), Fusarium graminearum-inoculated FHB-resistant accessions (RFg), and F. graminearum-inoculated FHB-susceptible accessions (SFg).

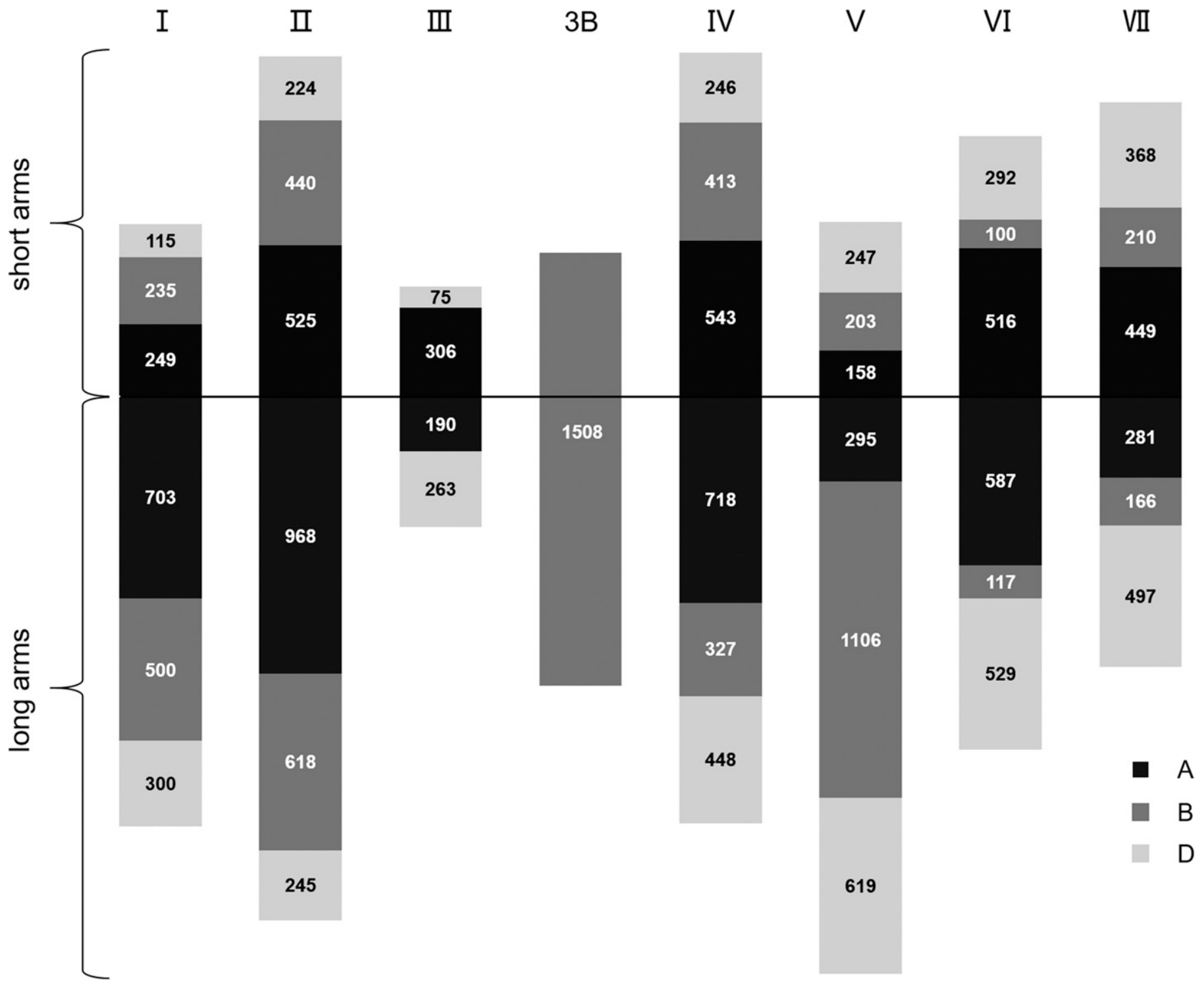

Fig. 2. Peptide distribution on the seven wheat chromosomes. 
spp. in resistant genotypes (Gunnaiah et al. 2012; Zhou et al. 2005), susceptible genotypes (Chetouhi et al. 2015; Zhou et al. 2006), or both (Ding et al. 2011). These studies identified 15 to 101 differentially accumulated proteins. From the gel-free approach presented herein, a nonredundant list of differentially accumulated proteins identified in this study was compiled: in total, 632 proteins were found in at least one of the four comparisons: RFg versus $\mathrm{RM}, \mathrm{SFg}$ versus SM, RM versus SM, and RFg versus SFg. When comparing the protein lists from each of the five studies with the nonredundant list generated here, there was a 15 to $37 \%$ overlap in the proteins identified (Supplementary Table S5). Meanwhile, when comparing each of the five studies one on one, less than $10 \%$ (and in some cases even less than 5\%) overlap was observed. Notably, PR proteins, POD, malate dehydrogenase, alcohol dehydrogenase, GAPDH, and PPIase are frequently identified as Fusarium-responsive proteins.

Proteins within the consensus QTL intervals. We carried out an exhaustive review of 17 QTL intervals previously reported in the genotypes of the resistant pool to construct a consensus map underlying these QTL, and these QTL were distributed on all of the wheat chromosomes except 1D, 4A, 4D, 6A, 6D, and 7B. Proteins were projected to the target QTL regions, and the proteins localized within these QTL intervals were counted (Table 1). In total, 404 proteins were mapped onto the target QTL intervals - and, among these, 38 proteins were differentially accumulated among the four different comparisons. Those with only one peptide hit were not considered, including three proteins localized within the QTL on 2BL. In all, 81 proteins hit the QTL on 3BSc, 4 of which were differentially accumulated; and 13,16 , and 9 proteins were projected onto the QTL on 2DS, 5AS, and 6BS chromosomes, respectively. None of the proteins are aligned with the fine-mapped $F h b 1$ interval on 3BS, and the proteins falling into the QTL on 3DL, 5BL, 6BS, and $7 \mathrm{AL}$ did not show significant differences in abundance among the four pairs. Seven differentially accumulated proteins are located within the QTL on 7DL, flanked by GWM44 and WMC702.
RT-qPCR validation of proteomics data. The putative genes encoding five of the differentially accumulated proteins were selected for RT-qPCR validation (Fig. 5). The differential gene expression patterns generally correspond with the observed protein accumulation. Transcripts of $P R-1$ and FLAVONE $O$ METHYLTRANSFERASE 1 (TaCOMT1) were upregulated in both $\mathrm{RFg}$ and $\mathrm{SFg}$ but showed no significance between the two pools. No difference in protein accumulation or gene expression of PR-1 was observed between RFg and SFg. Although TaCOMT1 differed in protein accumulation between the two inoculated pools, no difference in gene expression was observed for these two comparisons. An ATPbinding cassette (ABC) SUBFAMILY C TRANSPORTER (ABCC) was upregulated in $\mathrm{SFg}$ when compared with either SM or RFg, and protein accumulation patterns reflected this trend. The opposite trend was observed for GROUP 3 LATE EMBRYOGENESIS ABUNDANT PROTEIN (G3LEA) and PURPLE ACID PHOSPHATASE (PAP), both of which were downregulated in SFg compared with either SM or RFg. The putative PAP protein showed an accumulation pattern similar to that of the PAP transcript, whereas no peptide matching G3LEA was detected in SM and SFg. In addition, PAP displayed no significance between RM and RFg at either the transcript level or protein accumulation, whereas G3LEA was upregulated in RFg as compared with RM.

\section{DISCUSSION}

This is the first article on the F. graminearum-wheat interaction that focuses on the proteomics of rachis tissues in wheat. A highthroughput bulked proteomics approach was employed in order to remove genotype-specific responses, thereby enabling a holistic comparison of resistance versus susceptibility. Multiple genotypes were pooled from either FHB-resistant or -susceptible sources for differential protein analysis. Differentially accumulated proteins were associated with known QTL for FHB resistance, in hopes of facilitating the identification of resistant genes linked to these QTL.
A

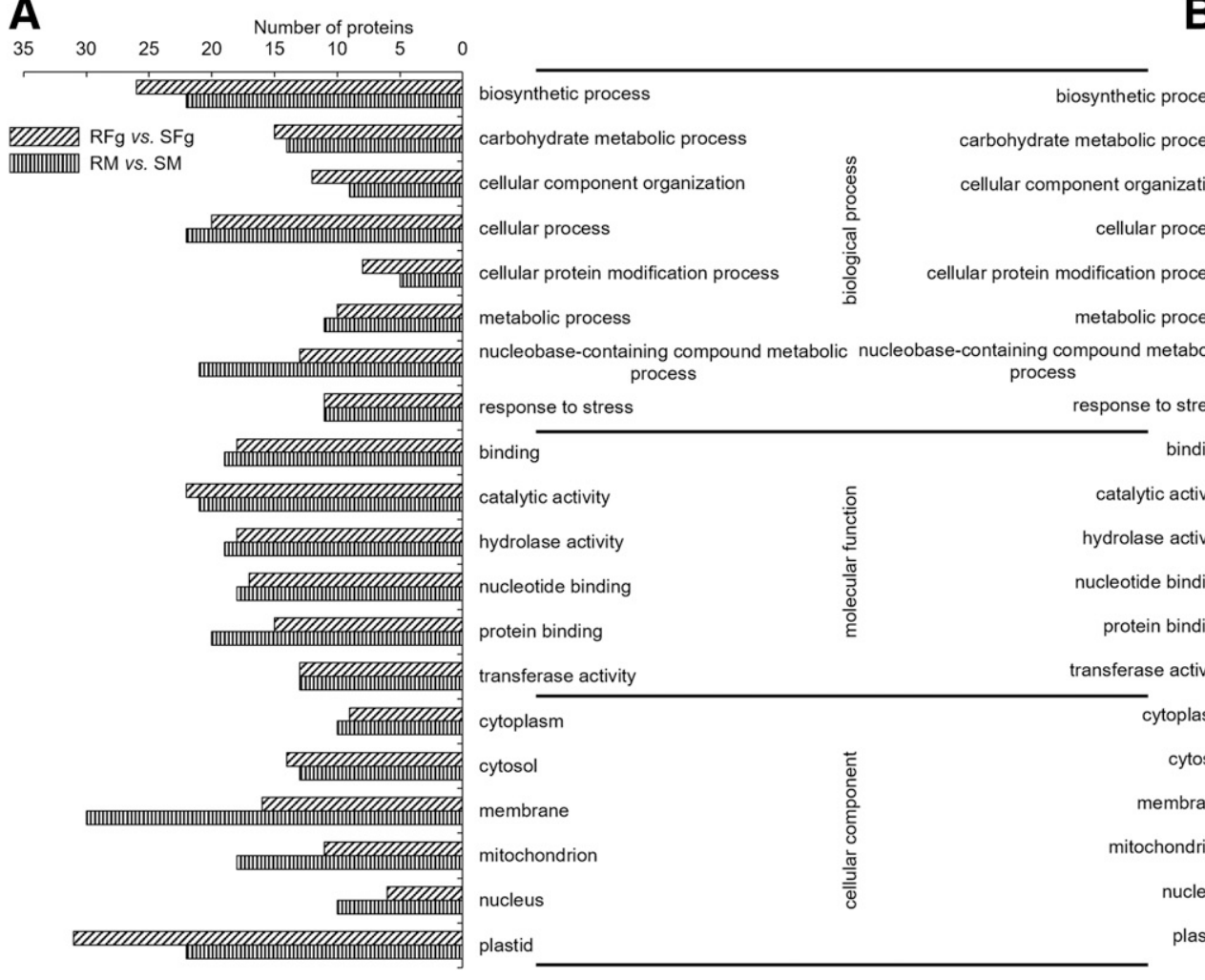

B

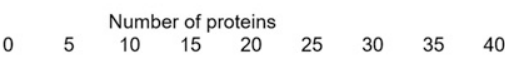

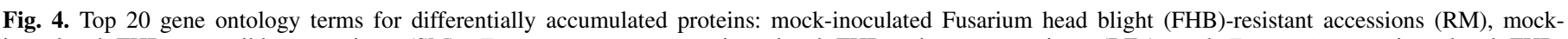

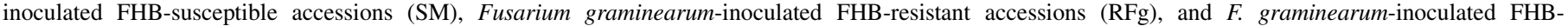
susceptible accessions (SFg). A, RFg versus SFg and RM versus SM and B, RFg versus RM and SFg versus SM. 
It is anticipated that this information will benefit breeding programs through the development of diagnostic markers.

$P R$ genes are involved in the plant defense response against different pathogens. In the host response to $\mathrm{FHB}$, differential transcript (Golkari et al. 2009; Xiao et al. 2013) and protein (Ding et al. 2011; Gunnaiah et al. 2012; Zhou et al. 2005, 2006) accumulation has been reported for numerous $P R$ genes. In the work presented herein, seven PR proteins-PR-1, PR-2, PR-3 (chitinase), PR-4 (Wheatwin-1), and PR-5 (thaumatin-like protein), PR-10 (ribonuclease-like protein), and PR-14 (nsLTP)—were differentially accumulated in response to $F$. graminearum. However, in the case of PR-4 and PR-10, only single peptide matches were observed, thereby reducing confidence in the identity assigned for these two gene products. Gene expression analysis validated the $F$. graminearum-induced upregulation of $P R-1$ in both resistant and susceptible pools (Fig. 5), suggesting that $P R-1$ accumulation might not be exclusive to resistant or susceptible genotypes. Similarly, other groups have shown that expression of $P R-1$ through -5 is upregulated by $F$. graminearum in both resistant and susceptible wheat (Pritsch et al. 2000). However, an earlier or stronger response of $P R$ expression may contribute to a resistance response (Bernardo et al. 2007; Pritsch et al. 2000).

Members of the PR-14 family, nsLTP, were more pronounced in the F. graminearum-treated susceptible pool ( $\mathrm{SFg}$ ) than that in the resistant one (RFg). Interestingly, constitutive or transgenic overexpression, as opposed to induced expression, of various LTP have been associated with resistant phenotypes (Foroud et al. 2012; Schweiger et al. 2013; Zhu et al. 2012). It should also be noted that a subset of wheat nsLTP were previously found to have antifungal activity toward $F$. graminearum in axenic cultures (Sun et al. 2008).

$P R$ gene expression is often regulated by plant signaling hormones. For example, jasmonic acid (JA) and ethylene (ET) coregulate $P R-3, P R-4$, and $P R-12$ (also called $P D F 1.2$ ) genes. Both the JA and ET pathways have been implicated in the FHB resistance response (Gottwald et al. 2012; Li and Yen 2008; Makandar et al. 2010; Qi et al. 2016). In this work, accumulation of ET and JA

TABLE 1. Consensus quantitative trait loci region known for Fusarium head blight resistance flanked by two markers

\begin{tabular}{|c|c|c|c|c|}
\hline \multirow[b]{2}{*}{ Chromosome } & \multirow[b]{2}{*}{ Intervals } & \multicolumn{2}{|c|}{ Proteins $(n)$} & \multirow[b]{2}{*}{ Wheat variety } \\
\hline & & Mapped $^{\mathrm{a}}$ & Accumulated $^{\mathrm{b}}$ & \\
\hline $1 \mathrm{AS}$ & WMC24-WMC120 & 55 & 3 & Huangfangzhu \\
\hline $1 \mathrm{AL}$ & WMC59-BARC158 & 8 & 1 & Wangshuibai \\
\hline $1 \mathrm{BS}$ & BARC128-GWM18 & 29 & 2 & Wangshuibai, Huangfangzhu \\
\hline 2AS & BARC212-GWM515 & 55 & 8 & Ning 7840, Wangshuibai \\
\hline $2 \mathrm{BL}$ & GWM120-BARC101 & 0 & 0 & Tokai-66, Ning 7840 \\
\hline 2DS & GWM296-GWM484 & 13 & 3 & Wangshuibai, Sumai 3, Nyubai \\
\hline $3 \mathrm{AS}$ & GWM2-GWM674 & 33 & 2 & Tokai-66, Baishanyuehuang, Wangshuibai, Huangcandou \\
\hline 3BS & BARC133-SNP7 & 0 & 0 & $\begin{array}{l}\text { Baishanyuehuang, Huangcandou, Huangfangzhu, Ning 7840, Sumai3, } \\
\text { Wangshuibai, Tokai-66, Nyubai, Taiwan Wheat }\end{array}$ \\
\hline 3BSc & GWM566-GWM131 & 81 & 4 & Nyubai, Wangshuibai, Huangcandou \\
\hline 3DL & GWM664-GWM645 & 4 & 0 & Wangshuibai \\
\hline $4 \mathrm{BL}$ & WMC511-WMC349 & 43 & 4 & Wangshuibai \\
\hline 5AS & GWM205-GWM129 & 16 & 3 & Nyubai, Baishanyuehuang, Huangfangzhu, Wangshuibai \\
\hline $5 \mathrm{BL}$ & GWM335-GWM371 & 9 & 0 & Wangshuibai \\
\hline $5 \mathrm{DL}$ & CFD57-GWM212 & 4 & 1 & Wangshuibai \\
\hline $6 \mathrm{BS}$ & GWM518-GWM644 & 9 & 0 & Sumai3, Wangshuibai \\
\hline $7 \mathrm{AL}$ & GWM276-GWM282 & 4 & 0 & Sumai3, Wangshuibai, Huangfangzhu \\
\hline $7 \mathrm{DL}$ & GWM44-WMC702 & 41 & 7 & Wangshuibai \\
\hline
\end{tabular}

a Number of mapped proteins.

b Number of differentially accumulated proteins.
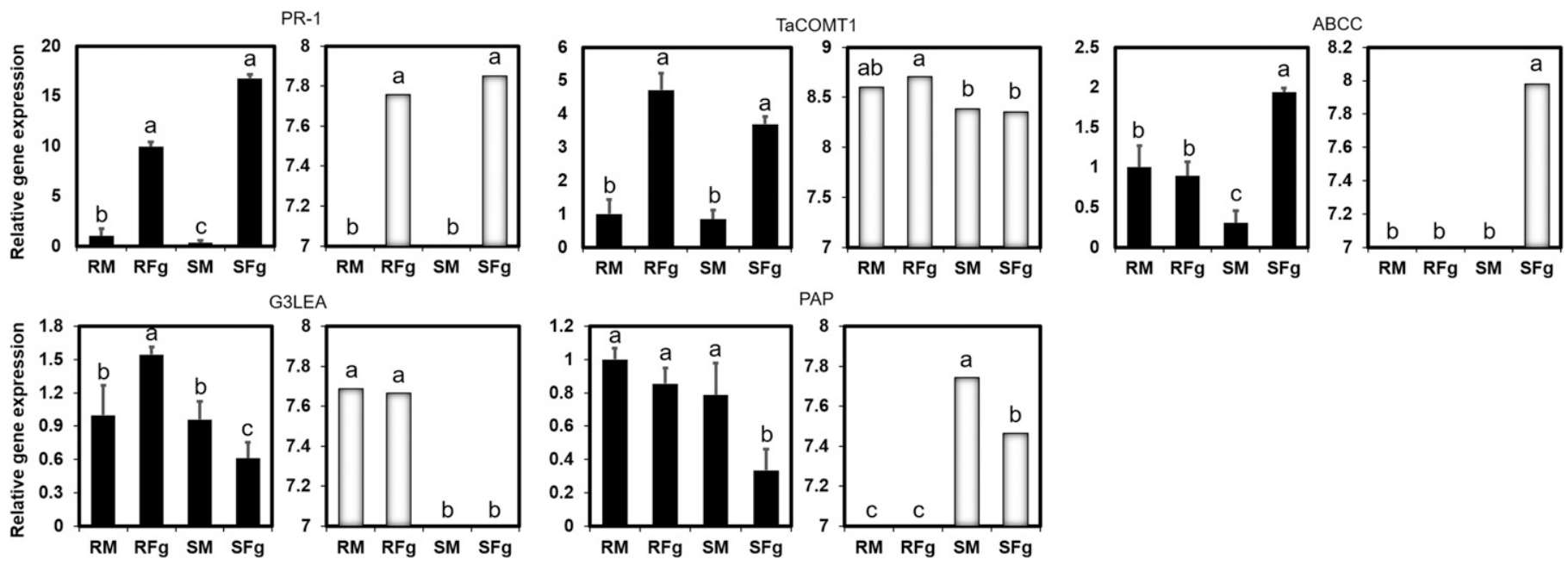

Fig. 5. Changes in relative gene expression (black bars) and protein accumulation (white bars) of five wheat genes. Pools: mock-inoculated Fusarium head blight (FHB)-resistant accessions (RM), mock-inoculated FHB-susceptible accessions (SM), Fusarium graminearum-inoculated FHB-resistant accessions (RFg), and F. graminearum-inoculated FHB-susceptible accessions (SFg). Reverse-transcription quantitative polymerase chain reaction data were normalized to the reference gene TaActin, where the relative expression of this gene was set to 1 in RM. Label-free quantitation intensity data (protein) from each experiment was log 10 transformed. $\mathrm{PR}-1$ = pathogenesis-related protein 1, TaCOMT1 = flavone O-methyltransferase 1, ABCC = ATP-binding cassette subfamily C transporter, G3LEA = group 3 late embryogenesis abundant protein, and PAP = purple-acid phosphatase. 
biosynthesis enzymes 1-aminocyclopropane-1-carboxylate oxidase and 12-oxo-phytodienoic acid reductase 2 (OPR2), respectively, did not differ significantly among the four pools. The $O P R 2$ gene is located within the QTL on chromosome 7DL. However, OPR1 was upregulated in RFg compared with RM, suggesting that JA biosynthesis is activated at $3 \mathrm{dpi}$, if not sooner. Similar results were reported in a study on Fusarium crown rot disease of wheat; in their work, Powell et al. (2017) also measured JA but did not observe any changes in JA accumulation despite upregulation of $O P R$ transcripts.

Lignin biosynthesis can be positively regulated by JA signaling (Xue et al. 2008), and the activities of COMT and phenylalanine ammonia lyase (PAL) are involved in this process (https:// www.genome.jp/kegg-bin/show_pathway?ko00940+C00482). TaCOMT1 was markedly upregulated in the RFg pool compared with the SFg pool, whereas the level of TaCOMT1 transcript was not affected (Fig. 5). PAL catalyzes the first step of the phenylpropanoid pathway (Dixon et al. 2002). Unexpectedly, PAL was observed at a higher abundance in SFg when compared with either SM or RFg. This differs from previous reports of Fusarium-induced $P A L$ upregulation at the transcript level in Sumai 3 and CM82036 (Golkari et al. 2009; Steiner et al. 2009). The expression of this enzyme in a resistance response may have spatial or temporal order during wheat infection. Alternatively, PAL may not be specific to resistant genotypes.

In an effort to provide new insights into potential core factors behind QTL-mediated defense against FHB, 404 QTL-oriented proteins were distributed on 17 intervals, and the number of proteins falling into each QTL varied with the QTL and QTL interval size.

The Fhbl QTL from Sumai 3 was reported to encode a POREFORMING TOXIN-LIKE (PFT) gene conferring FHB resistance (Rawat et al. 2016). In the present study, all 10 resistant accessions in the bulk carry the PFT allele (Rawat et al. 2016), which is absent in all 6 susceptible accessions. Because the Chinese Spring reference genome does not carry $F h b l$, the peptide sequences identified in the current study were screened for matches directly against the encoded PFT gene product (accession number AOZ21512). Two peptide hits were observed (data not shown) in the resistant accessions but only in the mock-inoculated pool (RM). PFT was absent in the susceptible pools (SM or SFg) but was also not detected as part of the Fusarium response (i.e., RFg pool). The proteomic analysis presented here captured one time point after inoculation ( $3 \mathrm{dpi})$ in one tissue type (rachis node). It may be that Fusarium-induced PFT accumulation occurs in different tissues or at different times during the host-pathogen interaction. Recently, He et al. (2018) observed differences in the PFT expression profile patterns among 12 wheat varieties carrying the Sumai 3-derived Fhbl QTL. The reference genome derived from Chinese Spring, a susceptible accession, may be a masking factor for identifying proteins located within the $F h b 1$ region, as was the case for PFT.

It had also previously been proposed that the $F h b l$ locus encodes or regulates an enzyme with UDP-glycosyltransferase activity, which can detoxify DON by catalyzing the addition of a glucose at carbon-3, yielding DON-3-O-glucoside (Lemmens et al. 2005). In this study, two UDP-glycosyltransferases were identified in the proteome, neither of which were mapped to the Fhbl locus, and no significant changes were observed among the four pairs.

$\mathrm{ABC}$ transporters involved in trichothecene tolerance (Walter et al. 2015) have previously been detected with greater transcript abundance upon FHB challenge in resistant genotypes (Kosaka et al. 2015; Xiao et al. 2013). In the work presented herein, an ABCC positioned within the 3BSc QTL was higher in both transcript and protein abundance in the SFg than in the RFg pool. Wheat lines carrying $F h b 1$, on $3 \mathrm{BS}$, were previously discriminated from the null lines in an expression profile study (Walter et al. 2008). Meanwhile, three ABC transporters have been offered as candidate resistance QTL on chromosomes 2DS (Handa et al. 2008), 2DL (Biselli et al. 2018), and 6BS (Fhb2) (Cuthbert et al. 2007).
Plants generate reactive oxygen species (ROS) by activating numerous oxidases in response to adverse environmental and biotic stresses (Apel and Hirt 2004). ROS scavenging enzymes such as catalase (CAT) and POD are commonly upregulated as part of the defense response (Mittler et al. 2004). Differential expression of genes encoding ROS scavengers and their gene products have been described in the host response to Fusarium spp. (Boddu et al. 2006; Golkari et al. 2007; Zhou et al. 2005, 2006). Transcript-based comparisons of resistant versus susceptible genotypes have suggested that the ROS pathway is either more active in susceptible genotypes (Xiao et al. 2013) or upregulated earlier in resistant accessions (Ding et al. 2011; Foroud et al. 2012). In this study, although two CAT and eight POD (some of which were mapped to QTL) were identified, no remarkable pattern of accumulation was observed for these two classes of ROS scavengers. However, two other candidate for ROS metabolism (Li et al. 2008; Liu et al. 2011; Mowla et al. 2006; Veljanovski et al. 2006) were differentially accumulated: a $55-\mathrm{kDa}$ PAP protein (located on the 7DL QTL for FHB resistance) and the LEA protein G3LEA (mapped within the QTL on 4BL flanked by WMC511 and WMC349). Two additional LEA proteins are associated with the QTL localized on chromosome 1AL (flanked by WMC59 and BARC158); however, their accumulation patterns did not differ among the four pairs. The PAP protein was downregulated in the susceptible pool following inoculation with $F$. graminearum (SFg versus SM). Surprisingly, this protein was not detected in the resistant pools, whereas transcripts of the encoding gene were present in both RM and RFg (Fig. 5).

The G3LEA protein accumulated in the resistant pools but was undetected in the two susceptible pools. RT-qPCR shows that G3LEA is significantly increased in RFg as compared with its mock (RM) and also with SFg (Fig. 5). Of note, G3LEA was downregulated in the SFg when compared with the SM, whereas the encoded protein was not detected in either pool. Thus, G3LEA may play a positive role in regulating FHB resistance during fungal infection. Accumulation of LEA proteins and expression of genes involved in desiccation stress are predicted to protect cellular structures (Bray 1993; Tolleter et al. 2007; Welin et al. 1994). A barley HVA1 (LEA3) gene, a member of the G3LEA protein family, confers drought tolerance in transgenic wheat and rice (Sivamani et al. 2000; Xu et al. 1996). The LEA superfamily of proteins has been described with a vast array of functions involving the cytoskeleton, membrane stabilization, $\mathrm{Ca}^{2+}$ binding, and molecular chaperone activities (Hundertmark et al. 2011; Wise and Tunnacliffe 2004). Thus, in addition to or as part of their putative functions in protection against oxidative stress (Liu et al. 2011; Mowla et al. 2006), LEA proteins may have activities in cellular membrane channels and signal transduction.

By eliminating the genotype-specific responses through a bulked-proteomics approach, we have identified new candidates for FHB resistance (G3LEA) and susceptibility (PAP). In addition, numerous proteins previously reported in wheat or barley spikelets following Fusarium inoculation, including PR proteins, PAL, PPIase, and $\mathrm{ABC}$ transporters, were also found be differentially accumulated at the rachis node. By focusing the analysis on QTL regions for FHB resistance, these results can be used to further develop markers for wheat breeding programs.

\section{LITERATURE CITED}

Anderson, J. A., Stack, R. W., Liu, S., Waldron, B. L., Fjeld, A. D., Coyne, C., Moreno-Sevilla, B., Fetch, J. M., Song, Q. J., Cregan, P. B., and Frohberg, R. C. 2001. DNA markers for Fusarium head blight resistance QTLs its two wheat populations. Theor. Appl. Genet. 102:1164-1168.

Apel, K., and Hirt, H. 2004. Reactive oxygen species: Metabolism, oxidative stress, and signal transduction. Annu. Rev. Plant Biol. 55:373-399.

Bai, G., Kolb, F. L., Shaner, G., and Domier, L. L. 1999. Amplified fragment length polymorphism markers linked to a major quantitative trait locus controlling scab resistance in wheat. Phytopathology 89:343-348.

Ban, T., Kawad, N., Yanagisawag, A., and Takezaki, A. 2008. Progress and future prospects of resistance breeding to Fusarium head blight in Japan. Cereal Res. Commun. 36:23-29. 
Bernardo, A., Bai, G., Guo, P., Xiao, K., Guenzi, A. C., and Ayoubi, P. 2007. Fusarium graminearum-induced changes in gene expression between Fusarium head blight-resistant and susceptible wheat cultivars. Funct. Integr. Genomics 7:69-77.

Bernardo, A. N., Ma, H., Zhang, D., and Bai, G. 2012. Single nucleotide polymorphism in wheat chromosome region harboring for Fusarium head blight resistance. Mol. Breed. 29:477-488.

Biselli, C., Bagnaresi, P., Faccioli, P., Hu, X., Balcerzak, M., Mattera, M. G., Yan, Z., Ouellet, T., Cattivelli, L., and Vale, G. 2018. Comparative transcriptome profiles of near-isogenic hexaploid wheat lines differing for effective alleles at the 2DL FHB resistance QTL. Front. Plant Sci. 9:37.

Boddu, J., Cho, S., Kruger, W. M., and Muehlbauer, G. J. 2006. Transcriptome analysis of the barley-Fusarium graminearum interaction. Mol. PlantMicrobe Interact. 19:407-417.

Bray, E. A. 1993. Molecular responses to water deficit. Plant Physiol. 103: 1035-1040.

Buerstmayr, H., Ban, T., and Anderson, J. A. 2009. QTL mapping and markerassisted selection for Fusarium head blight resistance in wheat: A review. Plant Breed. 128:1-26.

Cai, J., and Bai, G. H. 2014. Quantitative trait loci for Fusarium head blight resistance in Huangcandou x 'Jagger' wheat population. Crop Sci. 54: 2520-2528.

Chetouhi, C., Bonhomme, L., Lecomte, P., Cambon, F., Merlino, M., Biron, D. G., and Langin, T. 2015. A proteomics survey on wheat susceptibility to Fusarium head blight during grain development. Eur. J. Plant Pathol. 141: 407-418.

Cox, J., and Mann, M. 2008. MaxQuant enables high peptide identification rates, individualized p.p.b.-range mass accuracies and proteome-wide protein quantification. Nat. Biotechnol. 26:1367-1372.

Cuthbert, P. A., Somers, D. J., and Brule-Babel, A. 2007. Mapping of Fhb2 on chromosome 6BS: A gene controlling Fusarium head blight field resistance in bread wheat (Triticum aestivum L.). Theor. Appl. Genet. 114:429-437.

Cuthbert, P. A., Somers, D. J., Thomas, J., Cloutier, S., and Brule-Babel, A. 2006. Fine mapping $F h b 1$, a major gene controlling fusarium head blight resistance in bread wheat (Triticum aestivum L.). Theor. Appl. Genet. 112: $1465-1472$.

Ding, L. N., Xu, H. B., Yi, H. Y., Yang, L. M., Kong, Z. X., Zhang, L. X., Xue, S. L., Jia, H. Y., and Ma, Z. Q. 2011. Resistance to hemi-biotrophic $F$. graminearum infection is associated with coordinated and ordered expression of diverse defense signaling pathways. PLoS One 6:e19008.

Dixon, R. A., Achnine, L., Kota, P., Liu, C. J., Reddy, M. S., and Wang, L. 2002. The phenylpropanoid pathway and plant defence-A genomics perspective. Mol. Plant Pathol. 3:371-390.

Foroud, N. A., Ouellet, T., Laroche, A., Oosterveen, B., Jordan, M. C., Ellis, B. E., and Eudes, F. 2012. Differential transcriptome analyses of three wheat genotypes reveal different host response pathways associated with Fusarium head blight and trichothecene resistance. Plant Pathol. 61: 296-314.

Geddes, J., Eudes, F., Laroche, A., and Selinger, L. B. 2008. Differential expression of proteins in response to the interaction between the pathogen Fusarium graminearum and its host, Hordeum vulgare. Proteomics 8: 545-554.

Golkari, S., Gilbert, J., Ban, T., and Procunier, J. D. 2009. QTL-specific microarray gene expression analysis of wheat resistance to Fusarium head blight in Sumai-3 and two susceptible NILs. Genome 52:409-418.

Golkari, S., Gilbert, J., Prashar, S., and Procunier, J. D. 2007. Microarray analysis of Fusarium graminearum-induced wheat genes: Identification of organ-specific and differentially expressed genes. Plant Biotechnol. J. 5: 38-49.

Gottwald, S., Samans, B., Luck, S., and Friedt, W. 2012. Jasmonate and ethylene dependent defence gene expression and suppression of fungal virulence factors: Two essential mechanisms of Fusarium head blight resistance in wheat? BMC Genomics 13:369.

Gunnaiah, R., Kushalappa, A. C., Duggavathi, R., Fox, S., and Somers, D. J. 2012. Integrated metabolo-proteomic approach to decipher the mechanisms by which wheat QTL (Fhbl) contributes to resistance against Fusarium graminearum. PLoS One 7:e40695.

Handa, H., Namiki, N., Xu, D., and Ban, T. 2008. Dissecting of the FHB resistance QTL on the short arm of wheat chromosome 2D using a comparative genomic approach: From QTL to candidate gene. Mol. Breed. 22: $71-84$

He, Y., Zhang, X., Zhang, Y., Ahmad, D., Wu, L., Jiang, P., and Ma, H. M. 2018. Molecular characterization and expression of $P F T$, an FHB resistance gene at the Fhb1 QTL in wheat. Phytopathology 108:730-736.

Hundertmark, M., Dimova, R., Lengefeld, J., Seckler, R., and Hincha, D. K. 2011. The intrinsically disordered late embryogenesis abundant protein LEA18 from Arabidopsis thaliana modulates membrane stability through binding and folding. Biochim. Biophys. Acta 1808:446-453.
International Wheat Genome Sequencing Consortium. 2014. A chromosomebased draft sequence of the hexaploid bread wheat (Triticum aestivum) genome. Science 345: Article 1251788.

Jansen, C., von Wettstein, D., Schafer, W., Kogel, K. H., Felk, A., and Maier, F. J. 2005. Infection patterns in barley and wheat spikes inoculated with wild-type and trichodiene synthase gene disrupted Fusarium graminearum. Proc. Natl. Acad. Sci. USA 102:16892-16897.

Kang, Z., and Buchenauer, H. 2000. Ultrastructural and cytochemical studies on the infection of wheat spikes by Fusarium culmorum as well as on degradation of cell wall components and localization of mycotoxins in the host tissue. Mycotoxin Res. 16:1-5.

Kosaka, A., Manickavelu, A., Kajihara, D., Nakagawa, H., and Ban, T. 2015. Altered gene expression profiles of wheat genotypes against Fusarium head blight. Toxins (Basel) 7:604-620.

Lemmens, M., Scholz, U., Berthiller, F., Dall'Asta, C., Koutnik, A., Schuhmacher, R., Adam, G., Buerstmayr, H., Mesterhazy, A., Krska, R., and Ruckenbauer, P. 2005. The ability to detoxify the mycotoxin deoxynivalenol colocalizes with a major quantitative trait locus for Fusarium head blight resistance in wheat. Mol. Plant-Microbe Interact. 18:1318-1324.

Li, G. L., and Yen, Y. 2008. Jasmonate and ethylene signaling pathway may mediate Fusarium head blight resistance in wheat. Crop Sci. 48:1888-1896.

Li, T., Bai, G. H., Wu, S. Y., and Gu, S. L. 2012. Quantitative trait loci for resistance to Fusarium head blight in the Chinese wheat landrace Huangfangzhu. Euphytica 185:93-102.

Li, T., Luo, M., Zhang, D., Wu, D., Li, L., and Bai, G. 2016a. Effective marker alleles associated with type 2 resistance to Fusarium head blight infection in fields. Breed. Sci. 66:350-357.

Li, T., Zhang, D. D., Zhou, X. L., Bai, G. H., Li, L., and Gu, S. L. 2016b. Fusarium head blight resistance loci in a stratified population of wheat landraces and varieties. Euphytica 207:551-561.

Li, W. Y., Shao, G., and Lam, H. M. 2008. Ectopic expression of GmPAP3 alleviates oxidative damage caused by salinity and osmotic stresses. New Phytol. 178:80-91.

Lin, F., Kong, Z. X., Zhu, H. L., Xue, S. L., Wu, J. Z., Tian, D. G., Wei, J. B., Zhang, C. Q., and Ma, Z. Q. 2004. Mapping QTL associated with resistance to Fusarium head blight in the Nanda2419 $\times$ Wangshuibai population. I. Type II resistance. Theor. Appl. Genet. 109:1504-1511.

Liu, G., Xu, H., Zhang, L., and Zheng, Y. 2011. Fe binding properties of two soybean (Glycine $\max$ L.) LEA4 proteins associated with antioxidant activity. Plant Cell Physiol. 52:994-1002.

Liu, S. Y., Hall, M. D., Griffey, C. A., and McKendry, A. L. 2009. Metaanalysis of QTL associated with Fusarium head blight resistance in wheat. Crop Sci. 49:1955-1968.

Livak, K. J., and Schmittgen, T. D. 2001. Analysis of relative gene expression data using real-time quantitative PCR and the $2^{-\Delta \Delta C T}$ method. Methods 25 : 402-408.

Luber, C. A., Cox, J., Lauterbach, H., Fancke, B., Selbach, M., Tschopp, J., Akira, S., Wiegand, M., Hochrein, H., and O'Keeffe, M. 2010. Quantitative proteomics reveals subset-specific viral recognition in dendritic cells. Immunity 32:279-289.

Makandar, R., Nalam, V., Chaturvedi, R., Jeannotte, R., Sparks, A. A., and Shah, J. 2010. Involvement of salicylate and jasmonate signaling pathways in Arabidopsis interaction with Fusarium graminearum. Mol. PlantMicrobe Interact. 23:861-870.

Mittler, R., Vanderauwera, S., Gollery, M., and Van Breusegem, F. 2004. Reactive oxygen gene network of plants. Trends Plant Sci. 9:490-498.

Mowla, S. B., Cuypers, A., Driscoll, S. P., Kiddle, G., Thomson, J., Foyer, C. H., and Theodoulou, F. L. 2006. Yeast complementation reveals a role for an Arabidopsis thaliana late embryogenesis abundant (LEA)-like protein in oxidative stress tolerance. Plant J. 48:743-756.

Pestka, J. J. 2010. Toxicological mechanisms and potential health effects of deoxynivalenol and nivalenol. World Mycotoxin J. 3:323-347.

Powell, J. J., Carere, J., Fitzgerald, T. L., Stiller, J., Covarelli, L., Xu, Q., Gubler, F., Colgrave, M. L., Gardiner, D. M., Manners, J. M., Henry, R. J., and Kazan, K. 2017. The Fusarium crown rot pathogen Fusarium pseudograminearum triggers a suite of transcriptional and metabolic changes in bread wheat (Triticum aestivum L.). Ann. Bot. 119:853-867.

Pritsch, C., Muehlbauer, G. J., Bushnell, W. R., Somers, D. A., and Vance, C. P. 2000. Fungal development and induction of defense response genes during early infection of wheat spikes by Fusarium graminearum. Mol. Plant-Microbe Interact. 13:159-169.

Qi, P. F., Balcerzak, M., Rocheleau, H., Leung, W., Wei, Y. M., Zheng, Y. L., and Ouellet, T. 2016. Jasmonic acid and abscisic acid play important roles in host-pathogen interaction between Fusarium graminearum and wheat during the early stages of Fusarium head blight. Physiol. Mol. Plant Pathol. 93:39-48.

Rawat, N., Pumphrey, M. O., Liu, S., Zhang, X., Tiwari, V. K., Ando, K., Trick, H. N., Bockus, W. W., Akhunov, E., Anderson, J. A., and Gill, B. S. 2016. Wheat $F h b 1$ encodes a chimeric lectin with agglutinin domains and a 
pore-forming toxin-like domain conferring resistance to Fusarium head blight. Nat. Genet. 48:1576-1580.

Rogowska-Wrzesinska, A., Le, B. M., Thaysen-Andersen, M., and Roepstorff, P. 2013. 2D gels still have a niche in proteomics. J. Proteomics 88:4-13.

Schroeder, H. W., and Christensen, J. J. 1963. Factors affecting resistance of wheat to scab caused by Gibberella zeae. Phytopathology 53:831.

Schweiger, W., Steiner, B., Ametz, C., Siegwart, G., Wiesenberger, G., Berthiller, F., Lemmens, M., Jia, H., Adam, G., and Muehlbauer, G. J. 2013. Transcriptomic characterization of two major Fusarium resistance quantitative trait loci (QTLs), Fhb1 and Qfhs.ifa-5A, identifies novel candidate genes. Mol. Plant Pathol. 14:772-785.

Sivamani, E., Bahieldin, A., Wraith, J. M., Al-Niemi, T., Dyer, W. E., Ho, T. H. D., and Qu, R. D. 2000. Improved biomass productivity and water use efficiency under water deficit conditions in transgenic wheat constitutively expressing the barley HVA1 gene. Plant Sci. 155:1-9.

Steiner, B., Kurz, H., Lemmens, M., and Buerstmayr, H. 2009. Differential gene expression of related wheat lines with contrasting levels of head blight resistance after Fusarium graminearum inoculation. Theor. Appl. Genet. 118:753-764.

Sun, J. Y., Gaudet, D. A., Lu, Z. X., Frick, M., Puchalski, B., and Laroche, A. 2008. Characterization and antifungal properties of wheat nonspecific lipid transfer proteins. Mol. Plant-Microbe Interact. 21:346-360.

Tolleter, D., Jaquinod, M., Mangavel, C., Passirani, C., Saulnier, P., Manon, S., Teyssier, E., Payet, N., Avelange-Macherel, M. H., and Macherel, D. 2007. Structure and function of a mitochondrial late embryogenesis abundant protein are revealed by desiccation. Plant Cell 19:1580-1589.

Tyanova, S., Temu, T., Sinitcyn, P., Carlson, A., Hein, M. Y., Geiger, T., Mann, M., and Cox, J. 2016. The Perseus computational platform for comprehensive analysis of (prote)omics data. Nat. Methods 13:731-740.

Veljanovski, V., Vanderbeld, B., Knowles, V. L., Snedden, W. A., and Plaxton, W. C. 2006. Biochemical and molecular characterization of AtPAP26, a vacuolar purple acid phosphatase up-regulated in phosphate-deprived Arabidopsis suspension cells and seedlings. Plant Physiol. 142:1282-1293.

Walter, S., Brennan, J. M., Arunachalam, C., Ansari, K. I., Hu, X. J., Khan, M. R., Trognitz, F., Trognitz, B., Leonard, G., Egan, D., and Doohan, F. M. 2008. Components of the gene network associated with genotype-dependent response of wheat to the Fusarium mycotoxin deoxynivalenol. Funct. Integr. Genomics 8:421-427.

Walter, S., Kahla, A., Arunachalam, C., Perochon, A., Khan, M. R., Scofield, S. R., and Doohan, F. M. 2015. A wheat ABC transporter contributes to both grain formation and mycotoxin tolerance. J. Exp. Bot. 66:2583-2593.

Wang, Y., Yang, L., Xu, H., Li, Q., Ma, Z., and Chu, C. 2005. Differential proteomic analysis of proteins in wheat spikes induced by Fusarium graminearum. Proteomics 5:4496-4503.

Welin, B. V., Olson, A., Nylander, M., and Palva, E. T. 1994. Characterization and differential expression of $d h n / l e a / r a b$-like genes during cold acclimation and drought stress in Arabidopsis thaliana. Plant Mol. Biol. 26: 131-144.
Wise, M. J., and Tunnacliffe, A. 2004. POPP the question: What do LEA proteins do? Trends Plant Sci. 9:13-17.

Wiśniewski, J. R., Zougman, A., Nagaraj, N., and Mann, M. 2009. Universal sample preparation method for proteome analysis. Nat. Methods 6: 359-362.

Xiao, J., Jin, X., Jia, X., Wang, H., Cao, A., Zhao, W., Pei, H., Xue, Z., He, L., Chen, Q., and Wang, X. 2013. Transcriptome-based discovery of pathways and genes related to resistance against Fusarium head blight in wheat landrace Wangshuibai. BMC Genomics 14:197.

Xu, D., Duan, X., Wang, B., Hong, B., Ho, T., and Wu, R. 1996. Expression of a late embryogenesis abundant protein gene, HVA1, from barley confers tolerance to water deficit and salt stress in transgenic rice. Plant Physiol. 110:249-257.

Xue, Y. J., Tao, L., and Yang, Z. M. 2008. Aluminum-induced cell wall peroxidase activity and lignin synthesis are differentially regulated by jasmonate and nitric oxide. J. Agric. Food Chem. 56:9676-9684.

Yen, Y., Ibrahim, A. M. H., Malla, S., Berzonsky, W., Glover, K. D., and Stein, J. 2010. Quantitative trait loci analysis of novel Fusarium head blight resistance in Tokai 66. Am. J. Agric. Biol. Sci. 5:62-69.

Yu, J. B., Bai, G. H., Cai, S. B., and Ban, T. 2006. Marker-assisted characterization of Asian wheat lines for resistance to Fusarium head blight. Theor. Appl. Genet. 113:308-320.

Yu, J. B., Bai, G. H., Cai, S. B., Dong, Y. H., and Ban, T. 2008a. New Fusarium head blight-resistant sources from Asian wheat germplasm. Crop Sci. 48: 1090-1097.

Yu, J. B., Bai, G. H., Zhou, W. C., Dong, Y. H., and Kolb, F. L. 2008b. Quantitative trait loci for Fusarium head blight resistance in a recombinant inbred population of Wangshuibai/Wheaton. Phytopathology 98:87-94.

Zhang, X., Pan, H., and Bai, G. 2012. Quantitative trait loci responsible for Fusarium head blight resistance in Chinese landrace Baishanyuehuang. Theor. Appl. Genet. 125:495-502.

Zhou, W., Eudes, F., and Laroche, A. 2006. Identification of differentially regulated proteins in response to a compatible interaction between the pathogen Fusarium graminearum and its host, Triticum aestivum. Proteomics 6:4599-4609.

Zhou, W., Kolb, F. L., Yu, J., Bai, G., Boze, L. K., and Domier, L. L. 2004. Molecular characterization of Fusarium head blight resistance in Wangshuibai with simple sequence repeat and amplified fragment length polymorphism markers. Genome 47:1137-1143.

Zhou, W., Kolb, F. L., and Riechers, D. E. 2005. Identification of proteins induced or upregulated by Fusarium head blight infection in the spikes of hexaploid wheat (Triticum aestivum). Genome 48:770-780.

Zhu, X., Li, Z., Xu, H., Zhou, M., Du, L., and Zhang, Z. 2012. Overexpression of wheat lipid transfer protein gene TaLTP5 increases resistances to Cochliobolus sativus and Fusarium graminearum in transgenic wheat. Funct. Integr. Genomics 12:481-488.

Zou, C., Wang, P. X., and Xu, Y. B. 2016. Bulked sample analysis in genetics, genomics and crop improvement. Plant Biotechnol. J. 14:1941-1955. 